\title{
Maxillo-facial radiology case 155
}

\author{
SADJ October 2017, Vol 72 no 9429
}

CJ Nortjé

Below are clinical pictures and images of the most common malignancy which may present in the oral cavity. Describe the clinical and most obvious radiological features. What is your diagnosis?

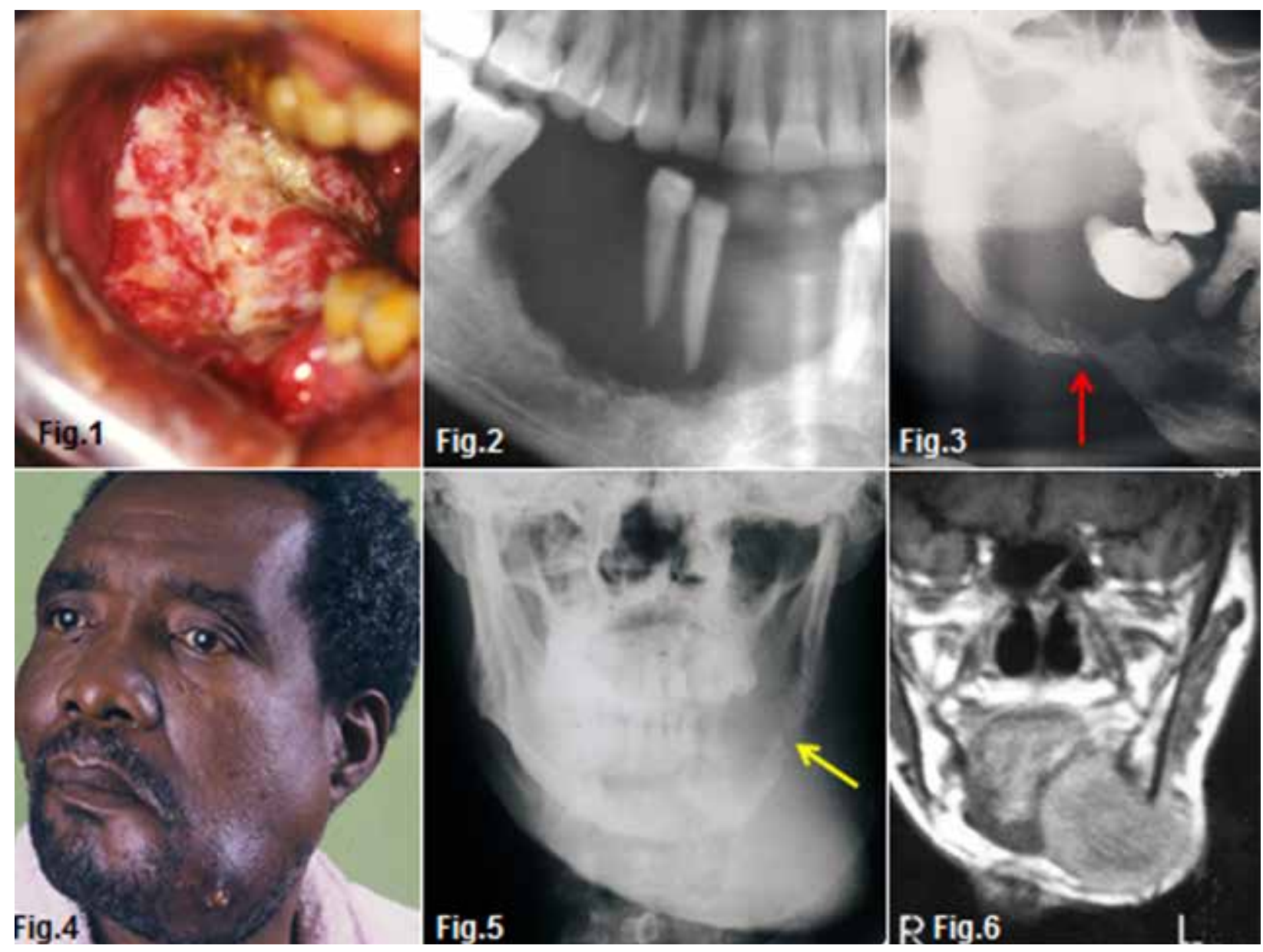

\section{INTERPRETATION}

Figs. 1 \& 2 show an ulcerative lesion of the alveolar bone with destruction of the bone adjacent to the intra-oral lesion. There is marked bone loss leading to "floating" teeth. A cropped pantomograph of another patient (Fig. 3) demonstrating a "floating" tooth and the presence of a pathologic fracture (red arrow) of the mandible. Figs. 4 \& 5 show the presence of a swelling with a draining sinus with extensive local involvement of the left mandible. Note the pathologic fracture in Fig. 5 (yellow arrow). Fig. 6 is a T2-weighted MRI image from the same patient. Note invasion of the lesion to the floor of mouth and destruction of both buccal and lingual cortical plates of the left mandible. The most obvious diagnosis of the above is primary carcinoma of the oral cavity and jaws. Carcinoma is the most common malignancy of the oral cavity. Certain geographic areas of the world have a high frequencies of oral cancer. For example, India has a high rate of oral squamous cell carcinoma. In the United States, squamous cell carcinoma makes up 4\% of all carcinomas in men and 2\% in women. Invasion of the jawbones by continuity is a frequent

CJ Nortjé: $B C h D, P h D, A B O M R, D S c$. Faculty of Dentistry, University of the Western Cape. E-mail: cnortje@uwc.ac.za occurrence in carcinomas originating in the alveolar ridge and the gingiva. Less frequent are osseous complications in carcinomas arising from the maxillary sinus, the hard palate, the buccal mucosa or the floor of the mouth. A comparison between the frequency of mandibular and maxillary osseous involvement in cases of oral mucosal carcinoma has shown a higher degree of invasion of the maxilla. Radiographic examination is important to determine whether the jawbone is involved in a soft tissue-originated carcinoma. In the mandible, the osseous involvement begins in most cases on top of the alveolar ridge, causing destruction of the underlying bone, in a U-shaped form. The edges may be distinct, ill-defined, or at times, slightly ragged and the lamina dura is totally destroyed (Fig. 2). There is no evidence of bone production within the excavation and no normal bone structures are recognizable in the affected area. A periosteal reaction is seldom seen. The bone is being destroyed through osteoclastic activity, and the marrow spaces are replaced by connective tissue which is the site of chronic inflammation. The spread of the carcinoma often occurs along the inferior dental neurovascular bundle.

\section{Reference}

1. Farman AG, Nortje CJ \& Wood R E: Oral and Maxillofacial Imaging, 1st Ed, Mosby. St. Louis, Missouri 1993 pp 307-311. 